\title{
Pulmonary abnormalities in obligate heterozygotes for cystic fibrosis
}

\author{
PAMELA B DAVIS, KATHRYN VARGO
}

From the Department of Pediatrics, Case Western Reserve University School of Medicine, and the Pulmonary Division, Veteran's Administration Medical Center, Cleveland, Ohio, USA

ABSTRACT Parents of children with cystic fibrosis have been reported to have a high prevalence of increased airway reactivity, but these studies were done in a select young, healthy, symptomless $\vec{N}$ population. In the present study respiratory symptoms were examined in 315 unselected parents of children with cystic fibrosis and 162 parents of children with congenital heart disease (controls). The cardinal symptom of airway reactivity, wheezing, was somewhat more prevalent in cystic fibrosis parents than in controls, but for most subgroups this increased prevalence did not reach statistical significance. Among those who had never smoked, $38 \%$ of obligate heterozygotes for cystic fibrosis but only $25 \%$ of the controls reported wheezing $(p<0.05)$. The cystic fibrosis parents who had never smoked but reported wheezing had lower $\mathrm{FEV}_{1}$ and $\mathrm{FEF}_{25-75}$, expressed as a percentage of $\overrightarrow{0}$ the predicted value, than control parents; and an appreciable portion of the variance in pulmonary function was contributed by the interaction of heterozygosity for cystic fibrosis with wheezing. For cystic fibrosis parents, but not controls, the complaint of wheezing significantly contributed to the prediction of pulmonary function $\left(F E V_{1}\right.$ and $\left.F_{E F} 5-75\right)$. In addition, parents of children with cystic fibrosis reported having lung disease before the age of 16 more than twice as frequently as control parents. Other respiratory complaints, including dyspnoea, cough, bronchitis, and hay fever, were as common in controls as in cystic fibrosis heterozygotes. These data are consistent with the hypothesis that heterozygosity for cystic fibrosis is associated with increased airway reactivity and its symptoms, and that the cystic fibrosis heterozygotes who manifest airway reactivity and its symptoms may be at risk for poor pulmonary function.

Cystic fibrosis, one of the most common genetic disorders of caucasians, is transmitted as an autosomal recessive trait; so the parents of a child with cystic fibrosis are obligate heterozygotes for the abnormal cystic fibrosis gene. At the molecular level heterozygotes almost certainly express the gene, though such expression may be masked or compensated for by other genes, and may be tissue specific. Detecting the expression of this gene in heterozygotes has, however, been difficult, even in the three tissues most consistently affected in homozygotes - the sweat gland, the pancreas, and the lung. Although, in most studies, the concentration of chloride in the sweat of obligate heterozygotes for cystic fibrosis was found to be greater than that of age matched controls, ${ }^{1}$ there is

Address for reprint requests: Dr Pamela B Davis, Pediatric Pulmonary Division, Rainbow Babies and Childrens Hospital, 2101 Adelbert Road, Cleveland, Ohio 44106, USA.

Accepted 28 August 1986 considerable overlap, and sweat chloride concentration cannot be used to identify cystic fibrosis heterozygotes. Pancreatic function in cystic fibrosis heterozygotes has not been evaluated with sensitive tests, but neutral fat excretion is normal. ${ }^{2}$ No pulmonary expression of the cystic fibrosis gene in heterozygotes has been clearly demonstrated. ${ }^{1-8}$

Pulmonary abnormalities can, however, be provoked in cystic fibrosis heterozygotes by a non- $N$ specific bronchial irritant: about one third of symp- $N$ tomless, medication free, young heterozygotes for $N$ cystic fibrosis have increased bronchial reactivity to methacholine. ${ }^{9}$ To pursue this observation, we investigated respiratory symptoms in a large number $\stackrel{\circ}{\leftarrow}$ of unselected individuals heterozygous for cystic $\stackrel{Ð}{\rightarrow}$ fibrosis to test the hypothesis that, if non-specific airway reactivity is more prevalent in cystic fibrosis het- 0 erozygotes, then the cardinal symptom of airway $\stackrel{\mathbb{D}}{\circ}$

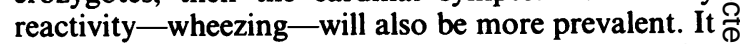
seemed important to test whether airway reactivity 
and its symptom are indeed prevalent inicystic fibrosis heterozygotes as a group, for airway reactivity has been postulated to be a risk factor for development and progression of obstructive airways disease. ${ }^{10-13}$ If they have a high prevalence of airway reactivity, cystic fibrosis heterozygotes might constitute a sizable (4-5\% of the white population) group at risk for airways obstruction.

\section{Methods}

\section{SUBJECTS}

Subjects gave consent to participate in this study, which was approved by the Institutional Review Board. Parents of children with cystic fibrosis were invited to participate as they accompanied their child on a clinic visit, visited the child in hospital, or volunteered to report on two special clinic days for the study. For all the children the diagnosis of cystic fibrosis was based on a sweat chloride concentration over $60 \mathrm{mEq}(\mathrm{mmol}) / 1$ and the presence of either pancreatic insufficiency or chronic obstructive pulmonary disease, or both. The only criteria for entry into the study for the parents were the biological relation to a child with cystic fibrosis and willingness to fill in the questionnaire and undergo spirometry. All available parents who visited the hospital during the study period participated (some, who visited only at weekends or late at night, were never contacted). The controls were the parents of children with congenital or acquired heart or circulatory disease attending the same ambulatory practice or admitted to the same hospital as the children with cystic fibrosis. The only entry criteria were the biological relationship to an ill child and willingness to participate. All parents available during the scheduled clinics we attended and all those in the wards when we visited were invited to participate; about one fifth declined, and no information on them is available. After data had been collected, for ease of analysis of pulmonary function test data, the study population was restricted to white subjects. This eliminated one heterozygote and seven control subjects, leaving 315 cystic fibrosis heterozygotes and 162 controls.

\section{QUESTIONNAIRE}

The ALA-DLD-78 questionnaire (basic version) was self administered. When help was requested, it was given in accordance with the directions of the epidemiology standardisation project. ${ }^{14}$ In addition, the diagnosis of the child in question was asked. Results were scored by hand and entered into DATATRIEVE, a database management program for the PDP 11/45 computer.

\section{SPIROMETRY}

Spirograms were performed on a Collins $8 \mathrm{~L}$ Survey
Spirometer according to the methods set out in the epidemiology standardisation project. ${ }^{14}$ Subjects stood and wore noseclips. Each subject recorded at least three acceptable spirograms, two within $5 \%$ of each other for FVC, and the best $\left(F V C+F E V_{1}\right)$ was used for analysis. Results were entered into DATATRIEVE. The values obtained were related to those predicted for age, sex, and height, the prediction equations of Knudson et al being used. ${ }^{15}$

\section{STATISTICAL ANALYSIS}

This analysis was performed with the BMDP statistical package on a PDP 11/45 computer, or with the STAT program on a Radio Shack Model II computer.

\section{Results}

\section{SUBJECTS}

The subjects completing the questionnaire are described in table 1 . The cystic fibrosis heterozygotes were older than the control parents. Although somewhat more of the controls had never smoked $(p=$ 0.08 ), the mean number of pack years consumed by the two groups did not differ. Sex distribution was similar in the two groups. Analyses of questionnaire answers were performed for the entire group of subjects and for subgroups stratified by sex and smoking habits. Non-smokers or never-smokers were defined as those who had not smoked (pack years $=0$ ).

\section{SYMPTOM COMPLAINTS}

Controls reported hay fever, dyspnoea, pneumonia, asthma, attacks of bronchitis, chronic bronchitis, and cough as frequently as cystic fibrosis heterozygotes (table 2).

Cystic fibrosis heterozygotes reported the presence of lung disease before the age of 16 twice as frequently as controls (table 2). These differences were significant in the initial analysis $(p=0.03$, Mantel-Haenszel extension of the $\chi^{2}$ test). The relative risk for history of lung disease before age 16 was $\mathbf{2 . 2 7}$ for the heterozygotes $(95 \%$ confidence interval 1.05-5.0). Correction, however, for the fact that answers to multiple questions not included in the original hypothesis were

Table 1 Questionnaire study population: cystic fibrosis heterozygotes $(\mathrm{HZ})$ and controls

\begin{tabular}{lcc}
\hline & $H Z$ & Controls \\
\hline Number & 315 & 162 \\
Age (y): mean (SD) & $41 \cdot 2(10 \cdot 4) *$ & $36 \cdot 2(7 \cdot 6)$ \\
$\quad$ range & $22-78$ & $20-61$ \\
Male: No (\%) & $112(36)$ & $54(33)$ \\
Never smokers: No (\%) & $129(41)$ & $80(49)$ \\
Pack years: mean (SD) & $11 \cdot 0(14 \cdot 8)$ & $9 \cdot 2(14 \cdot 4)$ \\
\hline
\end{tabular}

*Groups differ: $p<0.001$. 
Table 2 Respiratory complaints reported similarly by cystic fibrosis heterozygotes and controls

\begin{tabular}{|c|c|c|c|c|c|}
\hline \multirow[b]{2}{*}{ Complaint } & \multirow[b]{2}{*}{ Subjects } & \multicolumn{2}{|c|}{ No (\%) of subjects reporting symptoms } & \multirow{2}{*}{$\underset{\text { indiv }}{p}$} & \multirow{2}{*}{$\begin{array}{l}\text { p } \\
\text { multiple } \\
\text { samples }\end{array}$} \\
\hline & & Absent & Present & & \\
\hline Hayfever & $\begin{array}{l}\text { Heterozygotes } \\
\text { Controls }\end{array}$ & $\begin{array}{l}235(75) \\
111(78)\end{array}$ & $\begin{array}{l}78(25) \\
31(22)\end{array}$ & $>0.1$ & $>0.1$ \\
\hline $\begin{array}{l}\text { Attack } \\
\text { bronchitis }\end{array}$ & $\begin{array}{l}\text { Heterozygotes } \\
\text { Controls }\end{array}$ & $\begin{array}{l}225(72) \\
104(71)\end{array}$ & $\begin{array}{l}87(28) \\
42(29)\end{array}$ & $>0.1$ & $>0.1$ \\
\hline $\begin{array}{l}\text { Chronic } \\
\text { bronchitis }\end{array}$ & $\begin{array}{l}\text { Heterozygotes } \\
\text { Controls }\end{array}$ & $\begin{array}{l}295(93) \\
152(94)\end{array}$ & $\begin{array}{l}23(7) \\
10(6)\end{array}$ & $>0 \cdot 1$ & $>0.1$ \\
\hline Pneumonia & $\begin{array}{l}\text { Heterozygotes } \\
\text { Controls }\end{array}$ & $\begin{array}{l}235(75) \\
119(74)\end{array}$ & $\begin{array}{l}79(25) \\
42(26)\end{array}$ & $>0 \cdot 1$ & $>0 \cdot 1$ \\
\hline Cough & $\begin{array}{l}\text { Heterozygotes } \\
\text { Controls }\end{array}$ & $\begin{array}{l}248(78) \\
133(82)\end{array}$ & $\begin{array}{l}70(22) \\
29(18)\end{array}$ & $>0 \cdot 1$ & $>0.1$ \\
\hline Dyspnoea & $\begin{array}{l}\text { Heterozygotes } \\
\text { Controls }\end{array}$ & $\begin{array}{l}217(69) \\
123(76)\end{array}$ & $\begin{array}{l}97(31) \\
39(24)\end{array}$ & 0.09 & 0.72 \\
\hline Asthma & $\begin{array}{l}\text { Heterozygotes } \\
\text { Controls }\end{array}$ & $\begin{array}{l}294(92) \\
153(94)\end{array}$ & $\begin{array}{r}24(8) \\
9(6)\end{array}$ & $>0 \cdot 1$ & $>0 \cdot 1$ \\
\hline $\begin{array}{c}\text { Lung disease } \\
\text { before } 16 y\end{array}$ & $\begin{array}{l}\text { Heterozygotes } \\
\text { Controls }\end{array}$ & $\begin{array}{l}274(88) \\
153(94)\end{array}$ & $\begin{array}{l}38(12) \\
9(6)\end{array}$ & 0.03 & $0 \cdot 24$ \\
\hline
\end{tabular}

Table 3 Subjects reporting wheeze

\begin{tabular}{|c|c|c|c|c|}
\hline & \multicolumn{2}{|c|}{ No $(\%)$ of heterozygotes } & \multicolumn{2}{|c|}{ No $(\%)$ of controls } \\
\hline & $\begin{array}{l}\text { All } \\
(n=314)\end{array}$ & $\begin{array}{l}\text { Non-smokers } \\
(n=131)\end{array}$ & $\begin{array}{l}A l l \\
(n=161)\end{array}$ & $\begin{array}{l}\text { Non-smokers } \\
(n=80)\end{array}$ \\
\hline $\begin{array}{l}\text { Wheeze (any) } \\
\text { With cold } \\
\text { Apart from cold } \\
\text { Most of time }\end{array}$ & $\begin{array}{l}146(46) \\
106(34) \\
71(22)^{*} \\
17(5)\end{array}$ & $\begin{array}{l}49(38)^{*} \\
37(29) \\
21(16) \\
3(2)\end{array}$ & $\begin{array}{c}63(39) \\
57(35) \\
23(14) \\
5(3)\end{array}$ & $\begin{array}{c}20(25) \\
19(24) \\
9(11) \\
1(1)\end{array}$ \\
\hline
\end{tabular}

${ }^{*} \mathrm{p}<0.05$ ( $\chi^{2}$ test with Mantel-Haenszel extension).

analysed (by the formula $\left.p=1-(1-p)^{n}\right)$ reduced the $p$ value to 0.24 for the difference between heterozygotes and controls in the answer to this question. Those who reported lung disease before age 16 had a lower $\mathrm{FEV}_{1}$, forced mid expiratory flow $\left(\mathrm{FEF}_{25-75}\right)$, and $\mathrm{FEV}_{1}$ /forced vital capacity (FVC) ratio than those who did not when results were stratified for cigarette history, whether they were heterozygotes or

Table 4 Pulmonary function in non-smokers (mean values with standard deviations in parentheses)

\begin{tabular}{lll}
\hline & $\begin{array}{l}\text { Wheeze } \\
(n=69)\end{array}$ & $\begin{array}{l}\text { No wheeze } \\
(n=142)\end{array}$ \\
\hline & $F E V_{1}(\% \text { pred })^{*}$ & \\
Heterozygotes $(\mathrm{n}=131)$ & $98.0(12.5)$ & $103.5(15.2)$ \\
Controls $(\mathrm{n}=80)$ & $104 \cdot 7(17.6)$ & $100.0(12.4)$ \\
& $F E F_{25}-75(\% \text { pred })^{*}$ & \\
Heterozygotes & $92.0(27.4)$ & $103.4(28.0)$ \\
Controls & $105.6(25.0)$ & $100.1(20.4)$ \\
& $F E V_{1} / F V C(\%) \dagger$ & \\
Heterozygotes & $79.1(9.2)$ & $80.7(6.5)$ \\
Controls & $82.5(5.9)$ & $81.7(5.2)$ \\
\hline
\end{tabular}

*Interaction of complaint of wheezing and cystic fibrosis heterozygosity significant: $p<0.03$ (ANOVA).

tDiagnosis of the child accounts for a significant portion of the variance: $p<0.04$ (ANOVA).

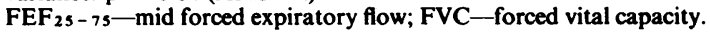

controls.

Cystic fibrosis heterozygotes as a group reported 3 wheezing somewhat more frequently than controls, although for most subgroups the difference did not? achieve significance. The biggest difference between $>$ all heterozygotes and controls occurred in answer to question 10-2, "Do you ever wheeze apart from a $\times$ cold?" (table 3). More smokers than non-smokers

Table 5 Pulmonary function in all subjects (mean values with standard deviations in parentheses)

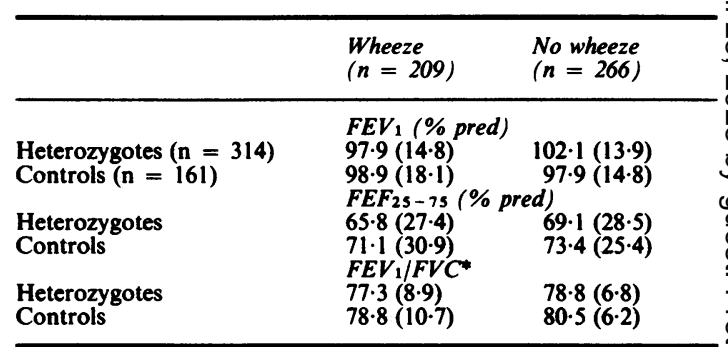

* Both the diagnosis of the child and the complaint of wheezing contribute significantly $(p<0.05$ ) to the variance.

Abbreviations as in table 4. 
wheezed. Among those who had never smoked, $38 \%$ of heterozygotes but only $25 \%$ of controls had wheezed at some time $(p<0.05)$. Reports of wheeze among never-smokers were more common for both male and female heterozygotes and for all questions about wheeze (with a cold, apart from a cold, or most of the time) than among controls, but for the most part these differences did not reach significance. The age distribution of those who wheezed is statistically indistinguishable from the age distribution of those who deny wheezing for all subjects (cystic fibrosis heterozygotes and controls), for heterozygotes alone, and for heterozygotes and controls who never smoked. For example, wheezing was as common in heterozygote never-smokers over 50 years as in those under $50(36 \% v 38 \%)$.

Heterozygous never-smokers who wheezed had lower $\mathrm{FEV}_{1}$ and $\mathrm{FEF}_{25-75}$ (\% predicted) values ${ }^{11}$ and a lower $\mathrm{FEV}_{1} / \mathrm{FVC}$ ratio than other non-smokers (table 4). The FEV $/$ FVC ratio was lower in heterozygotes than controls whether they wheezed or not, but for the flows the interaction of heterozygosity for cystic fibrosis and the complaint of wheezing was significant, indicating that the complaint of wheezing among non-smoking heterozygotes identifies a subpopulation with reduced airflow. Although the same trends were evident for the entire study group and for smokers and non-smokers, they did not achieve statistical significance (table 5).

\section{Discussion}

Parents of children with cystic fibrosis have increased airway reactivity to methacholine. ${ }^{9}$ Thirty per cent of heterozygotes but fewer than $5 \%$ of controls had their FEV $_{1}$ reduced by $20 \%$ in response to less than $3 \mathrm{mg} / \mathrm{ml}\left(\mathrm{PC}_{20} \mathrm{FEV}_{1}<3 \mathrm{mg} / \mathrm{ml}\right) .{ }^{9}$ The degree of airway reactivity, however, was for the most part mild. Among 50 heterozygotes with no admitted lung disease and normal baseline pulmonary function, the lowest $\mathrm{PC}_{20} \mathrm{FEV}_{1}$ for methacholine was $0.6 \mathrm{mg} / \mathrm{ml}$. $^{9}$ This concentration, however, is only at the median $\mathrm{PC}_{20} \mathrm{FEV}_{1}$ for a group of very mildly affected symptomless, unmedicated asthmatic subjects studied in the same laboratory at the same time $(0.78 \mathrm{mg} / \mathrm{ml}) .{ }^{16}$ For this reason, it may not be surprising that the excess prevalence of wheezing in the cystic fibrosis heterozygote population is small (table 3), and that there is no statistically significant increase in the prevalence of asthma (table 2). Nevertheless, the complaint of wheezing among heterozygotes seems to have some functional significance, for it identifies a subgroup with reduced airflow (table 4).

The excess prevalence of wheezing among heterozygous never-smokers could be due to overreporting of symptoms, to the cystic fibrosis gene, or to factors apart from the cystic fibrosis gene. Alternatively, a child with cystic fibrosis born into a household with parents who wheeze might be more likely to have the disease diagnosed, so the identification of parents by their relation to a child with known cystic fibrosis might bias the population of identified heterozygotes toward those who wheeze.

Cystic fibrosis heterozygotes might notice and report respiratory symptoms in themselves more readily because they look for them in their children. Most pulmonary symptoms, however, were not more prevalent in the cystic fibrosis heterozygotes (table 2). If cystic fibrosis heterozygotes overreport wheezing, then the pulmonary function of heterozygotes who complain of wheeze should be no worse than that of controls who wheeze, but in fact heterozygous neversmokers who wheezed had lower FEV,$F^{25} F_{25}$, and FEV $1 / F V C$ than controls (table 4). Thus wheezing in cystic fibrosis heterozygotes is accompanied by objective pulmonary function changes. Overreporting of wheezing by heterozygotes thus seems unlikely.

Differences between the populations of heterozygotes and of controls unrelated to cystic fibrosis heterozygosity could produce more wheezing in heterozygotes. More heterozygotes than controls had smoked (table 1), but there is increased prevalence of wheezing even among those who had never smoked. Although the heterozygotes were older than controls (table 1), there was no difference in the reports of wheezing between cystic fibrosis heterozygote neversmokers above age 50 and up to 50, and the age distribution of cystic fibrosis heterozygotes who wheeze is the same as that of cystic fibrosis heterozygotes who deny wheeze, both for the entire group and for the never-smokers. Thus neither smoking nor age differences between cystic fibrosis heterozygotes and controls account for the increased prevalence of wheezing in cystic fibrosis heterozygotes.

The altered home environment produced by a child with cystic fibrosis might promote wheezing in the parents. For example, exposure of some parents to pancreatic extract powder by inhalation during the child's infancy might sensitise the airway. ${ }^{17}$ Since very few parents currently handling pancreatic extract powder were studied, for this explanation to be valid we must postulate an effect that extends beyond the period of exposure to account for the group differences. Moreover, since the introduction of microencapsulated pancreatic enzyme preparations, exposure of parents to aerosolised proteolytic enzymes has been greatly reduced. In the present study younger cystic fibrosis heterozygotes have a prevalence of wheezing similar to that of older heterozygotes (who were more likely to have been exposed to powdered pancreatic enzymes). Cystic fibrosis mothers and fathers have a similar prevalence of 
wheezing, though the mothers are more likely to have had intensive exposure to the home environment and the pancreatic enzymes. Thus the patterns in the data do not implicate pancreatic enzyme powder exposure in the excess of wheezing among heterozygotes.

Parents of children with cystic fibrosis may be exposed more often to viral respiratory infections, which can lead to increased airway reactivity, ${ }^{1819}$ or they may be more likely to become infected. Children with cystic fibrosis appear to acquire no more viral infections than other children of similar age, but the child with cystic fibrosis is more likely to develop symptoms. ${ }^{20} \mathrm{~A}$ child with symptoms might infect others in the household more readily. Or some combination of increased constitutional vulnerability and increased environmental exposure could operate to produce increased airway reactivity in cystic fibrosis heterozygotes.

Twice as many cystic fibrosis heterozygotes as controls, however, report lung disease before the age of 16 (table 2). If this can be confirmed in a study specifically aimed at testing this hypothesis, then some difference from the control population may occur in heterozygotes before exposure to the environment created by a child with cystic fibrosis. Other studies have shown that those who note lung disease early in life often are recalling childhood asthma, ${ }^{21}$ and in our study a positive correlation was noted between recall of lung disease before age 16 and asthma $(r=0.28$ for non-smokers, $p<0.01)$. If a test to detect cystic fibrosis heterozygotes in the general population becomes available, the hypothesis that the home environment created by a child with cystic fibrosis contributes to respiratory symptoms can be tested more directly.

A familial tendency toward wheezing, as noted above, might make the child with cystic fibrosis more likely to be diagnosed, and in this case heterozygotes identified by their relation to a child with known cystic fibrosis (as they were for this study) may not be representative of all cystic fibrosis heterozygotes. If this is true, however, and if the children are more likely to be diagnosed because of increased severity of respiratory illness, then these children might also have reduced life expectancy and also be preferentially removed from the pool of families attending the clinic from which the study population was drawn. It is therefore difficult to predict the impact of any relationship between parental respiratory symptoms and disease severity in the children on the study population.

It is possible that cystic fibrosis heterozygotes, by virtue of their genetic make up, are more vulnerable to airway reactivity and wheezing. The gene for cystic fibrosis itself might exert a direct effect on the airway, or the cystic fibrosis gene (or another gene common in cystic fibrosis heterozygotes) might render its bearer $\overrightarrow{\vec{A}}$ vulnerable to environmental influences (for example, infection, environmental pollutants, or cigarette? smoke) that may lead to airway reactivity.

Early investigations of the occurrence of lung dis $-\frac{\omega}{\nabla}$ ease in cystic fibrosis heterozygotes did not detect $\varrho$ differences from controls, ${ }^{3-6}$ probably for severalis reasons. Most earlier studies were looking for $\vec{\circ}$ confirmed diagnoses of diseases (such as asthma, emphysema, chronic bronchitis, often strictly defined) $\vec{\omega}$ in a young to middle aged population, but lacked the statistical power to detect even a twofold increase in $\vec{x}$ their prevalence. In our study, respiratory symptoms $\mathrm{N}$ as well as diagnoses confirmed by physicians wereị recorded for more than twice as many subjects as in $\vec{N}$ any of the previous studies. Standardised and vali- $O$ dated questionnaire instruments were not used for $ᄋ$ some of the earlier studies. Moreover, smoking habits were often not considered in the analysis of earlier $\mathbb{D}$ data, and so real differences between the experimental and control populations might be obscured (or spurious differences introduced).

In summary, pulmonary abnormalities can be $\vec{\oplus}$ revealed in cystic fibrosis heterozygotes by metha-. choline, and the major symptom of increased airway reactivity-wheezing-is somewhat more prevalent among heterozygotes than among controls. More- $\frac{\partial}{0}$ over, among heterozygotes the complaint of wheezing appears to identify a subgroup with reduced airflow $\bar{\square}$ (tables 4-5). If these abnormalities arise from a single $\underset{\vec{\prime}}{\overrightarrow{7}}$ abnormal gene for cystic fibrosis, then we can specu- $\frac{0}{3}$ late that (1) the basic defect in cystic fibrosis is expressed in the lungs of heterozygotes and should be demonstrable in the appropriate test system; (2) one gene for cystic fibrosis is sufficient to produce mild $\vec{\circ}$ lung abnormalities in the absence of infection, so the lung disease in patients homozygous for the disease is $\underset{\sigma}{-}$ not solely the consequence of chronic bacterial infec- 3 . tion; (3) study of heterozygotes (in whom the second-i ary consequences of infection and structural damage 3 will not obscure the initiating events) may elucidate $\mathrm{O}$ the pathogenesis of the lung disease in cystic fibrosis. Whether or not the cystic fibrosis gene itself con-o tributes to airway reactivity, a subpopulation of heterozygotes, those who wheeze, appear to be at risk for poorer pulmonary function or development and 0 progression (with an appropriate promoter) of N chronic obstructive lung disease. This hypothesis can ${ }_{\sigma}$ be tested directly in a study of a still larger number of $<$ heterozygotes and controls.

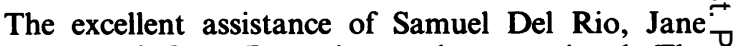
Root, and Gaye Paget is greatly appreciated. The assistance of the Cystic Fibrosis Center staff in recruiting and tracking subjects was invaluable. The $\frac{\rho}{\mathbb{D}}$ pediatric cardiology division kindly allowed access to $\varrho$ 
the parents of their patients. The help of Rachel Floyd in computerised data management and analysis is gratefully acknowledged. We thank Drs Pamela Byard and Naomi Breslau for helpful discussion of the statistics. This work was supported by grants from the Veterans Administration and the National Institutes of Health (HL28386, AM 27651), and PBD was a research associate of the Veterans Administration during most of the period of the study.

\section{References}

1 Di Sant'Agnese PA, Powell GF. The eccrine sweat defect in cystic fibrosis of the pancreas (mucoviscidosis). Ann NY Acad Sci 1962;93:555-99.

2 Wood JA, Fishman AP, Reemtsma K, Barker HG, di Sant'Agnese PA. A comparison of sweat chlorides and intestinal fat absorption in chronic obstructive pulmonary emphysema and fibrocystic disease of the pancreas. N Engl J Med 1959;260:951-6.

3 Hallett WY, Knudson AG, Massey FJ. Absence of detrimental effect of the carrier state for the cystic fibrosis gene. Am Rev Respir Dis 1965;90:714-24.

4 Anderson CM, Freeman M, Allan J, Hubbard L. Observations on (i) sweat sodium levels in relation to chronic respiratory disease in adults and (ii) the incidence of respiratory and other disease in parents and siblings of patients with fibrocystic disease of the pancreas. Med J Aust 1962;i:965-9.

5 Batten J, Muir D, Simon G, Carter C. The prevalence of respiratory disease in heterozygotes for the gene for fibrocystic disease of the pancreas. Lancet 1963;i: 1348-50.

6 Orzalesi MM, Kohner D, Cook CD, Shwachman H. Anamnesis, sweat electrolyte and pulmonary function studies in parents of patients with cystic fibrosis of the pancreas. Acta Paediat 1963;52:267-76.

7 Bernard E, Israel L, Debris MM. Chronic bronchitis and mucoviscidosis. Am Rev Respir Dis 1962;85:22-4.

$8 \mathrm{Karlish}$ AJ, Tarnoky AL. Mucoviscidosis as a factor in chronic lung disease in adults. Lancet 1960;ii:514-5.
9 Davis PB. Autonomic and airway reactivity in obligate heterozygotes for cystic fibrosis. Am Rev Respir Dis 1984;129:911-4.

10 Barter CE, Campbell AH. Relationship of constitutional factors and cigarette smoking to decrease in 1-second forced expiratory volume. Am Rev Respir Dis 1976;113:305-14.

11 Menkes HA. Airway reactivity and the need for a simple test. Am Rev Respir Dis 1980;121:619-20.

12 Britt EJ, Cohen B, Menkes H, et al. Airways reactivity and functional deterioration in relatives of COPD patients. Chest 1980;77:260-1.

13 Weiss ST. Increased levels of airways responsiveness as a risk factor for development of chronic obstructive lung disease. Chest 1984;86:3-4.

14 Ferris B. Epidemiology Standardization Project. Am Rev Respir Dis 1978;118:1-120.

15 Knudson RJ, Slatin RC, Lebowitz MD, Burrows B. The maximal expiratory flow-volume curve: normal standards, variability and effects of age. Am Rev Respir Dis 1976;113:587-600.

16 Davis PB, Simpson DM, Paget GL, Turi V. Betaadrenergic responses in drug-free asthmatic subjects. J Allergy Clin Immunol 1986;77:871-9.

17 Ganier M, Liberman P. IgE-mediated hypersensitivity to pancreatic extracts (PE) in parents of cystic fibrosis (CF) children. Clin Allergy 1979;9:125-32.

18 Empey DW, Laitinen LA, Jacobs L, Gold WM, Nadel JA. Mechanisms of bronchial hyperreactivity in normal subjects after upper respiratory tract infection. Am Rev Respir Dis 1976;113:131-9.

19 Hall WJ, Douglas GD Jr. Pulmonary function during and after common respiratory infections. Annu Rev Med 1980;31:233-8.

20 Ramsey BW, Cooney MK, Smith AL. Viral and mycoplasma infections in cystic fibrosis: do they play a significant role in pulmonary exacerbations? CF Club Abstracts 1984;25:161.

21 Burrows B, Knudson RJ, Lebowitz MD. The relationship of childhood respiratory illness to adult obstructive airway disease. Am Rev Respir Dis 1977;115:751-9. 